\title{
The Effects of Incretin Mimetics on Islet Cell Function in Type 2 Diabetes
}

\author{
Piero Marchetti, MD, PhD' ${ }^{1}$ and Ugo Boggi, MD
}

1. Professor of Endocrinology, Department of Endocrinology and Metabolism;

2. Associate Professor of Surgery, and Head, Division of General and Transplant Surgery in Uremic and Diabetic Patients, University of Pisa

DOI: 10.17925/USE.2008.04.2.75

The term incretins is used to denote intestinal hormones released in response to nutrient ingestion that are able to potentiate glucosestimulated insulin secretion. ${ }^{1,2}$ The communication between the intestine and the endocrine pancreas is demonstrated by the observation that the increase of plasma insulin levels following oral glucose administration is much greater than that seen after intravenous glucose. ${ }^{1-4}$ This phenomenon has been termed the 'incretin effect,' and accounts for $50-70 \%$ of the total insulin secreted after oral glucose..$^{1-4}$

The first incretin hormone to be identified was gastric inhibitory polypeptide (GIP), named because of its ability to reduce gastric acid secretion in dogs. However, this effect is seen at pharmacological doses, whereas the incretin action is observed at physiological levels. The hormone was therefore re-named glucose-dependent insulinotropic polypeptide, but retains the acronym GIP.

A second incretin hormone was discovered showing 50\% homology with glucagon, and named glucagon-like peptide-1 (GLP-1). Both GLP-1 (mainly from L cells in the distal intestine) and GIP (primarily produced by $K$ cells in the duodenum) are released within minutes following food ingestion and contribute to the rapid disposal of nutrients through several pathways, with the action on the pancreatic $\beta$ cell probably representing the most important mechanism. ${ }^{1-4}$ Their circulating levels decrease rapidly (the half-life of GLP-1 is approximately two minutes and that of GIP is approximately six minutes) due to enzymatic inactivation by dipeptidyl peptidase-4 (DPP-4). Both GIP and GLP-1 contain alanine at position two, which render them excellent substrates for DPP-4. ${ }^{1-4}$

The pleiotropic actions of incretins on the regulation of blood glucose have led to the concept that GLP-1 and/or GIP could be used in the treatment of type 2 diabetes. In type 2 diabetes GIP action is reduced, whereas its secretion does not seem to be altered. GLP-1 shows a lower insulinotropic effect. Individuals with type 2 diabetes show a small but significant reduction in meal-stimulated levels of GLP-1 and the action of this incretin remains relatively preserved, so most efforts have focused on GLP-1..$^{2-5}$ Two main classes of drug have been developed: GLP-1 receptor agonists resistant to the action of DPP-4 (GLP-1 mimetics) and inhibitors of DDP-4 (GLP-1 enhancers) (see Figure 1). ${ }^{2-5}$ This article will discuss the effects of GLP-1 and its mimetics on the function of pancreatic islets, particularly in the case of type 2 diabetes.

The Pancreatic Islets in Type 2 Diabetes

Type 2 diabetes is by far the most common form of diabetes, representing approximately $90 \%$ of all cases. ${ }^{6}$ It results from a combination of genetic and acquired factors that impair $\beta$-cell function and tissue insulin sensitivity. ${ }^{6,7}$ Increasing evidence shows that $\beta$-cell dysfunction, characterized by decreased $\beta$-cell mass and insulin secretion defects, is central to the onset and progression of this disease. ${ }^{7-9}$ In a normal pancreas there are approximately one million islets of Langerhans, which contain several different types of endocrine cell. The insulin-secreting $\beta$ cells represent the majority of islet endocrine cells (60-80\%), followed by glucagon-containing cells ( $\alpha$ cells, 20-30\%), somatostatin ( $\delta$ ) cells (5-15\%), and pancreatic polypeptide (PP) cells. $\beta$-cell mass is regulated by four major mechanisms: apoptosis (programmed cell death), size modification (hypo- and hyperplasia), replication (mitotic division of differentiated $\beta$ cells), and neogenesis (development from precursor cells). ${ }^{8-10}$ The amount of $\beta$-cell mass is given by the sum of replication, size, and neogenesis, minus the rate of apoptosis. The role of reduced $\beta$-cell mass in type 2 diabetes, the primary importance of $\beta$-cell apoptosis, and the insufficiency of replication/neogenesis have been studied by several authors. Decreased islet mass, reduced $\beta$-cell mass, and diminished $\beta$-cell insulin-secretory granules have been generally reported (see Figure 2)..$^{7-10}$ A few studies have shown increased $\alpha$-cell volume in the islets of patients with type 2 diabetes. ${ }^{11}$ This leads to alterations of insulin and glucagon secretion in type 2 diabetes. ${ }^{7-10,12-14}$ Commonly found quantitative abnormalities of insulin release include reduced or absent first-phase

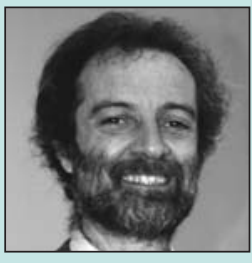

Piero Marchetti, MD, PhD, is a Professor of Endocrinology, Head of the Pancreatic Islets Research Laboratory, and Director of the Endocrinology and Metabolism of Organ and Cellular Transplantation Unit at the University of Pisa. His main areas of interest include the physiopathology of pancreatic $\beta$ cells, focusing on the mechanisms leading to $\beta$-cell dysfunction and death in type 1 and type 2 diabetes, and the role of pancreas and islet transplantation in the cure of type 1 diabetes. Professor Marchetti has published widely in the field of diabetes and has served as a reviewer for numerous journals. He has been/is involved in several research projects funded by the European Community and other international and national public and private organizations. He gained his MD and specialization in internal medicine at the University of Pisa and his PhD in endocrinology sciences at the University of Florence.

E: marchant@immr.med.unipi.it

Ugo Boggi, MD, is an Associate Professor of Surgery and Head of the Division of General and Transplant Surgery in Uremic and Diabetic Patients at the University of Pisa. He has performed over 4,000 interventions, covering all fields of general and minimally invasive surgery. His main areas of interest and specialization are pancreas oncology — he has performed over 400 pancreatectomies - and abdominal organ transplantation-he has performed over 1,000 grafts. As an academic surgeon, Dr Boggi has trained several generations of general and transplant surgeons and has provided many contributions to the medical literature. He graduated in medicine from the University of Pisa, where he also received most of his surgical training and conducted the majority of his research. 
Figure 1: Representation of GLP-1 (with the DPP-4 Cleaving Site), GLP-1 Mimetics (Exenatide and Liraglutide), and GLP-1 Enhancers (DPP-4 Inhibitors-Vildagliptin, Sitagliptin)

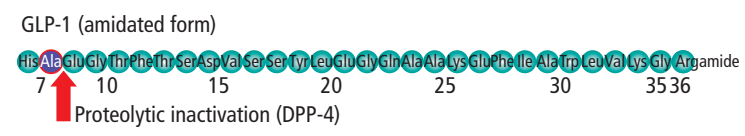

Exenatide
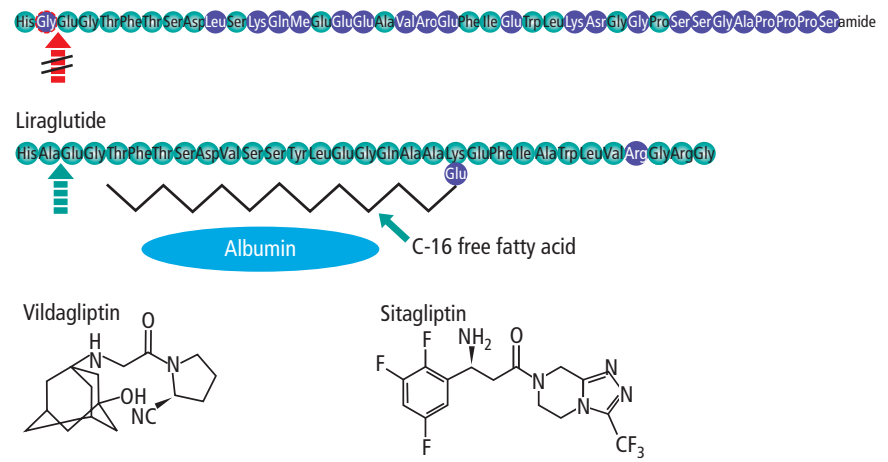

Adapted from Drucker and Nauck, 2006. ${ }^{5}$

Figure 2: Insulin Immunostaining (Brownish Color) of a Control (left) and a Type 2 Diabetic (right) Islet-In This Latter Case a Lower Amount of Cells Containing Insulin Is Demonstrated
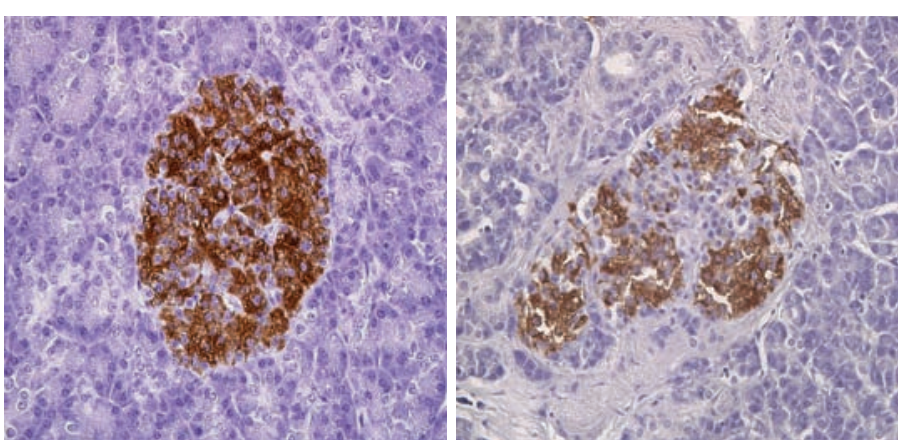

Courtesy of Professor Piero Marchetti.

Figure 3: Immunofluorescence Staining of Human Islet Cells Showing That GLP-1 Receptor Positivity (left) Is Associated with Insulin Positivity (right)
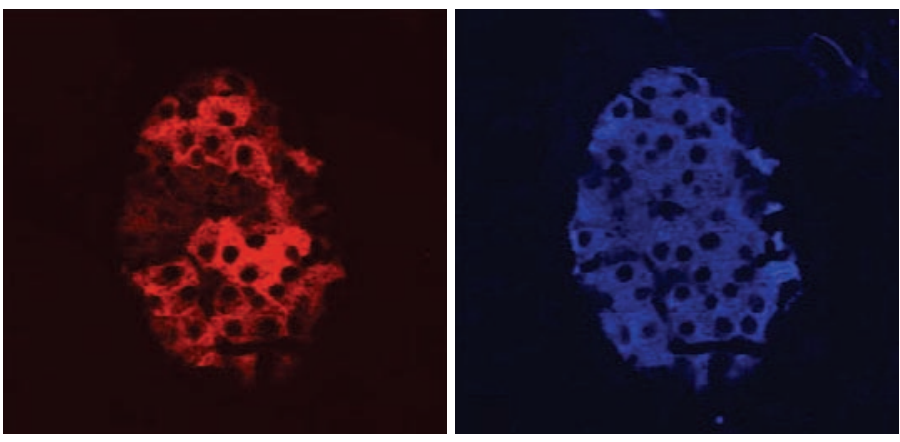

Adapted from Tornehave et al., 2008.16

insulin secretion to intravenous glucose, delayed or blunted responses to mixed meal ingestion, and, with time, reduced second-phase release and diminished responses to non-glucose stimuli. Qualitative defects in insulin release are represented, besides changes of early-phase insulin secretion, by alterations of oscillatory patterns and increased pro-insulin release. Alterations of glucagon secretion in type 2 diabetes include an inappropriately high release in relation to the prevailing glucose levels and increased secretion in response to arginine stimulation compared with subjects without diabetes. ${ }^{12-14}$

\section{Glucagon-like Peptide-1 Signaling Pathway and the} Pancreatic Islets

Human islets are well equipped with molecules involved in GLP-1 action. With the aim of exploring the potential of GLP-1 receptors as targets in nuclear medicine, Korner et al. investigated the GLP-1 receptor protein qualitatively and quantitatively in a large spectrum of human neoplastic and non-neoplastic tissues..$^{15}$ The technique of 125 -GLP1 amide receptor autoradiography showed that in the pancreas both islets and acini express GLP-1 receptors, with higher levels in the islets..$^{15}$ In a few cases of chronic pancreatitis, islets showed a lower GLP-1 receptor density, but the acinar GLP-1 receptor expression was unchanged. When immunostaining was performed in human pancreatic samples, it was found that GLP-1 receptor positivity was mostly found in $\beta$ cells and duct cells ${ }^{16,17}$ (see Figure 3). Molecular data showed the presence of molecules involved in GLP-1 signaling in human islets. Huypens et al. prepared islet cell aggregates (containing 50-60\% insulin-positive cells and 15-20\% glucagon-positive cells) from human pancreata. ${ }^{18}$ Gene expression of GLP-1 and GIP receptors was studied by Northern blots and reverse transcription-polymerase chain reaction (RT-PCR) analysis. All of the islet cell preparations consistently expressed both receptors (with GLP-1 showing higher expression). Liver and muscle samples were negative for GLP-1 and GIP receptors and fat showed GIP receptor expression. ${ }^{18}$ Marselli et al. performed extensive array analysis of gene expression in isolated human islets and $\beta$-cell-enriched preparations obtained by laser capture micro-dissection. This showed that, both in the whole islet cell population and in the $\beta$ cells, the expression of GLP-1 and GIP receptors could be detected, although at relatively low signal levels. ${ }^{19}$ Gene expression of molecules involved in post-receptor GLP-1 action, such as CAMP-response element-binding protein (CREB), protein-kinase CAMPdependent regulatory protein (PRKAR), and CAMP-regulated guanine nucleotide exchange factor 2 (Epac2), has been found in isolated human islets by quantitative RT-PCR experiments..$^{20}$

Glucagon-like Peptide-1, Incretin Mimetics, and the Function of Pancreatic Islets

The effects on pancreatic islet cells of acute and prolonged exposure to GLP-1 or insulin mimetics have been studied both in vivo in patients and using isolated human islets of Langerhans. Early work showed that when GLP-1 was infused for a few hours in patients with type 2 diabetes, glucose levels were normalized, insulin and C-peptide concentrations increased significantly, and plasma glucagon diminished. ${ }^{21}$ When normal glycemia was reached, insulin and C-peptide returned to basal levels and plasma glucose concentrations remained stable despite the ongoing infusion of GLP-1.21 This finding is of relevance, as it demonstrates that incretins reduce blood glucose levels without inducing hypoglycemia. In an extensive study where GLP-1 was given subcutaneously for six weeks in a group of 20 patients with type 2 diabetes, ${ }^{22}$ metabolic control improved significantly compared with that observed following placebo treatment. The hyperglycemic clamp technique was used to assess features of $\beta$-cell function and showed that C-peptide concentrations, first- and second- 
phase insulin secretion in response to glucose, and peak values of Cpeptide after arginine stimulation improved significantly with GLP-1 but not with saline treatment (see Figure 4). ${ }^{22}$ Fehse and colleagues studied a group of subjects with type 2 diabetes following short-term exposure to intravenous exenatide. ${ }^{23}$ They found that this GLP-1 mimetic could restore the first phase of insulin secretion in response to intravenous glucose in the patients with diabetes, who, in the absence of exenatide, did not display the normal dynamics of insulin release. ${ }^{23}$

The HOMA- $\beta$ index (Homeostasis Model Assessment of $\beta$-cell function) is a parameter that is often used in clinical studies to assess $\beta$-cell function. When an analysis was performed to assess the metabolic effects of exenatide based on interim evaluation of data from the extension of three double-blind, controlled trials, ${ }^{24}$ the authors found that the value of HOMA- $\beta$ improved significantly with exenatide with an increase of approximately $50 \%$ of the pre-treatment value. This was confirmed in a similar study published one year later ${ }^{25}$ and in a recently published article ${ }^{26}$ where Japanese patients with type 2 diabetes received liraglutide once daily (from 0.1 to $0.9 \mathrm{mg}$ ) for 14 weeks. In this latter study, compared with placebo treatment GLP-1 mimetic induced a significant increase of the HOMA- $\beta$ index.

In vivo studies allow for only the indirect evaluation of pancreatic islet function mainly due to the influences of many additional variables, including, in particular, the degree of insulin sensitivity and the prevailing glucose concentrations. Work has been carried out to assess the direct effects of incretins on human pancreatic islet cells by using isolated islets. Preliminary studies show that in the presence of $10 \mathrm{mmol} / \mathrm{l}$ glucose, $10 \mathrm{nmol} / \mathrm{l}$ GLP-1 could significantly potentiate insulin release, leading to a $30 \%$ increase. ${ }^{27}$ The potentiating effect was weaker at $2.8 \mathrm{mmol} / \mathrm{l}$ glucose. In that study, it was also observed that GLP-1 inhibited glucagon secretion and stimulated somatostatin and pancreatic polypeptide release. ${ }^{27}$ More extensive studies have been performed. Using islet cell preparations, it was observed that during a two-hour static incubation period, insulin release increased from $3.8 \pm 0.9$ to $12.6 \pm 2.1 \%$ of insulin content when glucose concentration in the incubation medium was raised from 2.5 to $10 \mathrm{mmol} / 1 .^{18}$

The addition of $10 \mathrm{nmol} / \mathrm{l}$ glucose GLP-1 in the medium containing $10 \mathrm{mmol} / \mathrm{l}$ glucose determined a two-fold increase of insulin secretion (which was similar to the effects induced by $10 \mathrm{nmol} / / \mathrm{GIP}$ or glucagon). ${ }^{18}$ Farilla et al. incubated isolated human islets prepared from three independent donors for five days in the presence or absence of $10 \mathrm{nmol} / \mathrm{l}$ GLP-1 (added every 12 hours), and performed survival, functional, and molecular studies. ${ }^{28}$ Better preservation of 3D islet morphology was observed in the GLP-1-exposed islets, which was associated with a two- to three-fold decrease in the number of apoptotic islet cells. Concomitantly, the anti-apoptotic molecule bcl-2 was upregulated and the expression of active caspase-3 (a crucial executor of apoptosis) was suppressed. Glucosestimulated insulin secretion was also studied. Exposure to GLP-1 enhanced the capability of the islets to respond to glucose $15 \mathrm{mmol} / \mathrm{l}$ glucose (no difference was found in response to $6 \mathrm{mmol} / /$ glucose). The effect was particularly clear after three days of culture. On day five all culture conditions showed a decrease in glucose-dependent insulin secretion. This was less prominent in islets cultured in the presence of GLP-1. These effects were accompanied by increased intracellular insulin content, suggesting that GLP-1 could promote insulin synthesis. ${ }^{28}$
Figure 4: C-peptide Concentrations During Hyperglycemic Clamp in Patients with Type 2 Diabetes Receiving Saline or GLP-1

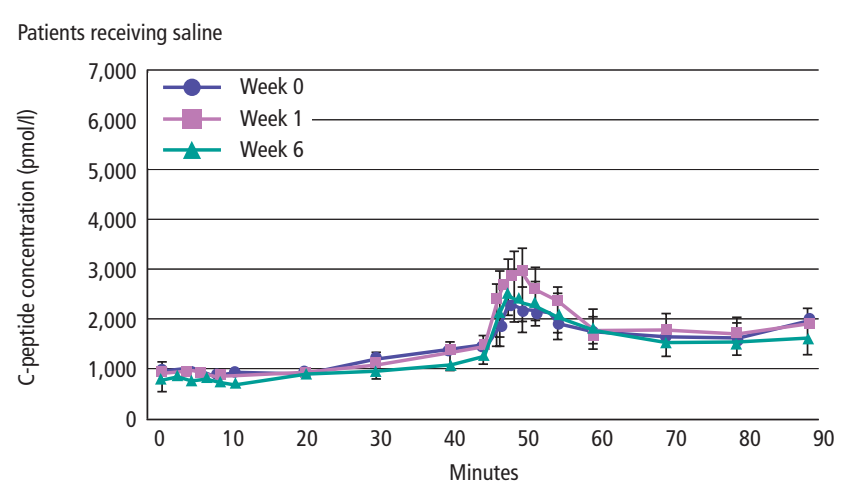

Patients receiving GLP-1

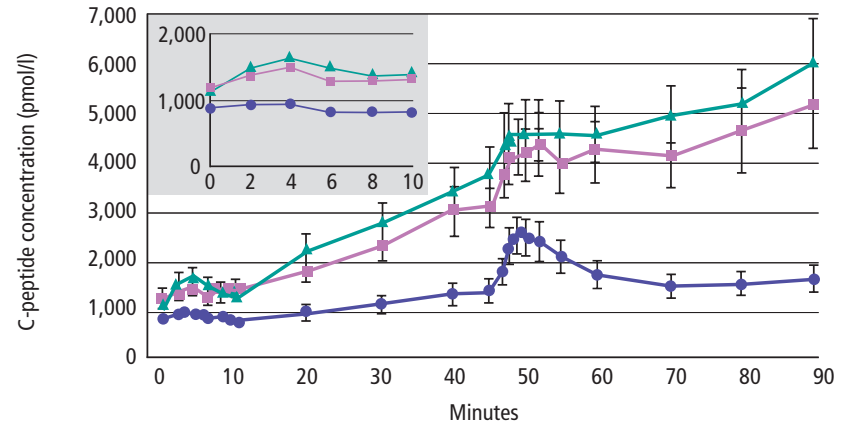

Insert shows first-phase responses (incremental 0-10 minutes) for patients receiving GLP-1 Adapted from Zander et al., 2002. ${ }^{22}$

Figure 5: Insulin Secretion in Response to 3.3 and $16.7 \mathrm{mmol} / \mathrm{l}$ Glucose from Islets of Patients with Type 2 Diabetes

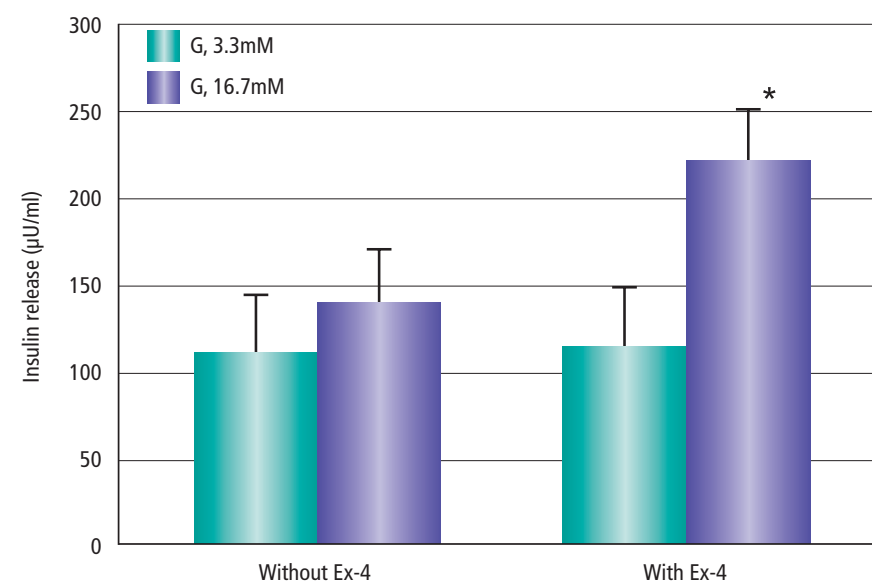

Pre-exposure with a GLP-1 mimetic (with EX-4) determined a recovery of glucose-induced insulin release in comparison with untreated islets (without Ex-4).

Adapted from Lupi et al., 2008. ${ }^{20}$

In a recently published paper, Lupi et al. obtained isolated human islets from the pancreas of 11 subjects without diabetes and seven individuals with type 2 diabetes of comparable age and body mass index. ${ }^{20}$ The islets were then cultured for two days at $5.5 \mathrm{mmol} / \mathrm{l}$ glucose, either with or without the addition of $10 \mathrm{nmol} / \mathrm{l}$ exendin-4. At the end of the incubation, the authors studied glucose-stimulated insulin secretion (acute challenge with 3.3 and $16.7 \mathrm{mmol} / \mathrm{l}$ glucose) and the expression of 
several genes involved in islet cell function and turnover. The diabetic islets, which were unresponsive initially, gained partial competence to glucose following exposure to exendin-4, as demonstrated by a $50 \%$ enhancement of insulin release at $16.7 \mathrm{mmol} / \mathrm{l}$ glucose (see Figure 5). It was observed that transcription of glucose transporter-2 (which facilitates glucose entry into the $\beta$ cell) and glucokinase (involved in the early step of glycolysis) was significantly increased, together with gene expression of insulin. Enhanced transcription of PDX-1 (a $\beta$-cell differentiation factor), Ki67 (a protein associated with cell proliferation) and cyclin D1 (a molecule involved in the cell cycle) was observed in the islets cultured with exendin-4. ${ }^{20}$

\section{Glucagon-like peptide-1 mimetics}

reduce plasma glucose in patients with

type 2 diabetes through a number of

mechanisms, with the action at the

level of the pancreatic islets playing

a major role.

Additional evidence that incretins can increase the expression of molecules involved in $\beta$-cell differentiation comes from the study performed by Brun et al. on the transcription factor Pax4. ${ }^{29}$ The authors found that Pax4 is expressed in human pancreatic islets and was increased in patients with type 2 diabetes with a body mass index below $26 \mathrm{~kg} / \mathrm{m}^{2}$, and long-term adiposity favored suppression of the gene. Following incubation for one and two days with $10 \mathrm{nmol} / \mathrm{l} \mathrm{GLP}-1$ or exendin-4, the authors showed that these two compounds had no significant effect on Pax4 expression when glucose concentration in the incubation medium was $5.6 \mathrm{mmol} / \mathrm{l}$. There was, however, a six-fold increase in Pax4 messenger RNA (mRNA) levels in the presence of $15 \mathrm{mmol} / /$ glucose. Zulewski and colleagues identified a distinct population of cells in human pancreatic islets and ducts that express nestin. ${ }^{30}$ These cells could be induced to differentiate in culture into cells with pancreatic, exocrine, endocrine, and hepatic phenotypes. The same group showed that nestin-positive cells have GLP-1 receptors and that exposure to $10 \mathrm{nmol} / \mathrm{l}$ GLP-1 stimulated differentiation into an endocrine phenotype expressing the homeodomain protein PDX-1 and the hormones insulin and glucagon. ${ }^{31}$

\section{Conclusion}

GLP-1 mimetics reduce plasma glucose in patients with type 2 diabetes through a number of mechanisms, with the action at the level of the pancreatic islets playing a major role. Established effects include potentiation of insulin release in response to increased glucose levels (with the return of insulin secretion to basal values when glucose concentrations normalize) and improvements of the dynamics of insulin secretion.

As shown by ex vivo studies with isolated islets, GLP-1 and its mimetics are able to modify several molecular features of the pancreatic islets, which allows the $\beta$ cells to sense glucose stimulation and contribute to an improvement of insulin release. Further studies are needed to establish whether the effects of incretins at the level of glucagon secretion are direct or mediated by the improved insulin secretion. The demonstrated ex vivo beneficial actions of GLP-1 and GLP-1 mimetics on human $\beta$-cell survival and regeneration need to be confirmed in the clinical setting.
1. Baggio LL, Drucker DJ, Biology of incretins: GLP-1 and GIP, Gastroenterology, 2007;132:2131-57.

2. Vilsbøll T, Holst JJ, Incretins, insulin secretion and Type 2 diabetes mellitus, Diabetologia, 2004;47:357-66.

3. Nauck MA, Baller B, Meier JJ, Gastric inhibitory polypeptide and glucagon-like peptide-1 in the pathogenesis of type 2 diabetes, Diabetes, 2004;53(3):S190-96.

4. Ahren B, Gut peptides and type 2 diabetes treatment, Curr Diab Rep, 2003;3:365-72.

5. Drucker DJ, Nauck MA, The incretin system: glucagon-like peptide1 receptor agonists and dipeptidyl peptidase-4 inhibitors in type 2 diabetes, Lancet, 2006;368:1696-1705.

6. American Diabetes Association, Diagnosis and Classification of Diabetes Mellitus, Diabetes Care, 2008;31:S55-S60.

7. Stumvoll M, Goldstein BJ, Van Haeften TW, Pathogenesis of type 2 diabetes, Endocr Res, 2007:32:19-37.

8. Donath MY, Halban PA, Decreased beta-cell mass in diabetes: significance, mechanisms and therapeutic implications, Diabetologia, 2004;47:581-9.

9. Meier JJ, Beta cell mass in diabetes: a realistic therapeutic target? Diabetologia, 2008;51:703-13.

10. Marchetti $P$, Dotta F, Lauro D, Purrello F, An overview of pancreatic beta-cell defects in human type 2 diabetes: Implications for treatment, Regul Pept, 2007;146:4-11.

11. Yoon $\mathrm{KH}, \mathrm{Ko} \mathrm{SH}$, Cho JH, et al., Selective beta-cell loss and alphacell expansion in patients with type 2 diabetes in Korea, J Clin Endocrinol Metab, 2003;88:2300-2308.

12. Unger RH, Aguilar-Parada E, Muller WA, Eisentraut AM, Studies of pancreatic alpha cell function in normal and diabetic subjects, J Clin Invest, 1970;49:847-8.

13. Ohneda A, Watanabe K, Horigome K, et al., Abnormal response of pancreatic glucagon to glycemic changes in diabetes mellitus, $J$ Clin Endocrinol Metab, 1978;46:504-10.
14. Hamaguchi T, Fukushima H, Uehara M, et al., Abnormal glucagon response to arginine and its normalization in obese hyperinsulinemic patients with glucose intolerance: importance of insulin action onpancreatic alpha cells, Diabetologia, 1991;34:801-6.

15. Körner M, Stöckli M, Waser B, Reubi JC, GLP-1 receptor expression in human tumors and human normal tissues: potential for in vivo targeting, J Nucl Med, 2007;48:736-43.

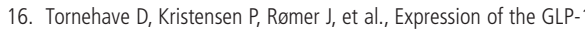
receptor in mouse, rat, and human pancreas, I Histochem Cytochem, 2008;56:841-51.

17. Xu G, Kaneto H, Lopez-Avalos MD, et al., GLP-1/exendin-4 facilitates beta-cell neogenesis in rat and human pancreatic ducts, Diabetes Res Clin Pract, 2006;73:107-10.

18. Huypens $P$, Ling Z, Pipeleers $D$, Schuit F, Glucagon receptors on human islet cells contribute to glucose competence of insulin release, Diabetologia, 2000;43:1012-19.

19. Marselli L, Thorne J, Ahn YB, et al., Gene expression of purified beta-cell tissue obtained from human pancreas with laser capture microdissection, J Clin Endocrinol Metab, 2008;93:1046-53.

20. Lupi R, Mancarella R, Del Guerra S, et al., Effects of exendin-4 on islets from type 2 diabetes patients, Diabetes Obes Metab, 2008;10:515-19.

21. Nauck MA, Kleine N, Orskov C, et al., Normalisation of fasting hyperglycaemia by exogenous glucagon-like peptide 1 (7-36 amide) in type 2 (non-insulin-dependent) diabetic patients, Diabetologia, 1993;36:741-4.

22. Zander M, Madsbad S, Madsen JL, Holst JJ, Effect of 6-week course of glucagon-like peptide 1 on glycaemic control, insulin sensitivity, and beta-cell function in type 2 diabetes: a parallelgroup study, Lancet, 2002;359:824-30.

23. Fehse F, Trautmann M, Holst JJ, et al. Exenatide augments firstand second-phase insulin secretion in response to intravenous glucose in subjects with type 2 diabetes, I Clin Endocrinol Metab, 2005;90:5991-7.

24. Buse JB, Klonoff DC, Nielsen LL, et al., Metabolic effects of two years of exenatide treatment on diabetes, obesity, and hepatic biomarkers in patients with type 2 diabetes: an interim analysis of data from the open-label, uncontrolled extension of three doubleblind, placebo-controlled trials, Clin Ther, 2007;29:139-53.

25. Klonoff DC, Buse JB, Nielsen LL, et al., Exenatide effects on diabetes, obesity, cardiovascular risk factors and hepatic biomarkers in patients with type 2 diabetes treated for at least 3 years, Curr Med Res Opin, 2008;24:275-86.

26. Seino Y, Rasmussen MF, Zdravkovic M, Kaku K, Dose-dependent improvement in glycemia with once-daily liraglutide without hypoglycemia or weight gain: A double-blind, randomized, controlled trial in Japanese patients with type 2 diabetes, Diabetes Res Clin Pract, 2008;81:161-8.

27. Fehmann $H C$, Hering BJ, Wolf MJ, et al., The effects of glucagonlike peptide-I (GLP-I) on hormone secretion from isolated human pancreatic islets, Pancreas, 1995;11:196-200.

28. Farilla L, Bulotta A, Hirshberg B, et al., Glucagon-like peptide 1 inhibits cell apoptosis and improves glucose responsiveness of freshly isolated human islets, Endocrinology, 2003;144: 5149-58.

29. Brun T, He KH, Lupi R, et al., The diabetes-linked transcription factor Pax4 is expressed in human pancreatic islets and is activated by mitogens and GLP-1, Hum Mol Genet, 2008;17:478-89.

30. Zulewski H, Abraham EJ, Gerlach MJ, et al., Multipotential nestinpositive stem cells isolated from adult pancreatic islets differentiate ex vivo into pancreatic endocrine, exocrine, and hepatic phenotypes, Diabetes, 2001;50:521-33.

31. Abraham EJ, Leech CA, Lin JC, et al., Insulinotropic hormone glucagon-like peptide-1 differentiation of human pancreatic isletderived progenitor cells into insulin-producing cells, Endocrinology, 2002;143:3152-61. 